\title{
Tecnologias educativas no contexto escolar: estratégia de educação em saúde em escola pública de Fortaleza- $\mathrm{CE}^{1}$
}

\author{
Educational technology in the school context: strategy for health education in \\ a public school in Fortaleza-CE
}

\section{Tecnología educativa en el contexto escolar: estrategia para la educación en salud en una escuela pública en Fortaleza-CE}

\author{
Fabiane do Amaral Gubert', Ana Carolina Lobo dos Santos"', Katiana Araújo Aragão"I, \\ Dayse Christina Rodrigues Pereira ${ }^{\mathrm{IV}}$, Neiva Francenely Cunha Vieira ${ }^{\mathrm{V}}$, \\ Patricia Neyva da Costa Pinheiro ${ }^{\mathrm{VI}}$
}

\footnotetext{
${ }^{1}$ Tecnologia Educacional e os modelos de educação em saúde nas ações de enfermagem e promoção da saúde. CNPq.

Enfermeira. Discente do Mestrado em Enfermagem da Universidade Federal do Ceará (UFC), bolsista CAPES. Email: fabianequbert@hotmail.com.

"Estudante de graduação em Enfermagem da UFC, bolsistas de iniciação científica. Email: carolina.acls@yahoo.com.br.

II' Estudante de graduação em Enfermagem da UFC, bolsistas de iniciação científica. Email: katian22@hotmail.com

IV Estudante de graduação em Enfermagem da UFC. Email: daysechristina@oriontelecom.com.br.

$\checkmark$ Enfermeira. PhD em Educação em Saúde; Docente do Programa de Pós-Graduação em Enfermagem da UFC. Diretora da Faculdade de Farmácia Odontologia e Enfermagem da UFC. Email: neivafrancenely@hotmail.com.

vI Enfermeira. Doutora em Enfermagem; Docente do Programa de Pós-Graduação em Enfermagem da UFC. Email: neyva.pinheiro@yahoo.com.br.
}

\section{RESUMO}

O objetivo deste estudo é abordar o uso de tecnologias educativas como estratégia de educação em saúde junto a adolescentes no contexto escolar. A coleta de dados ocorreu entre abril e maio de 2007 em uma escola pública municipal na cidade de Fortaleza-CE, por meio de um ciclo de quatro oficinas educativas realizadas com 30 adolescentes. As oficinas tiveram o intuito promover a reflexão/ação junto aos participantes sobre as temáticas: sexualidade, gênero, DST/AIDS e métodos contraceptivos. Estudo do tipo pesquisa-ação, de abordagem qualitativa, apoiado no Modelo Pedagógico de Paulo Freire. Os resultados evidenciaram lacunas no conhecimento quanto às formas de infecção pelas DST e uso adequado de métodos contraceptivos. Outro dado refere-se às questões de gênero que parecem influenciar na qualidade de vida dos jovens do estudo. O uso de tecnologias educativas pôde despertar entre os adolescentes, um repensar sobre a vivência da saúde sexual e reprodutiva a partir das vulnerabilidades percebidas. Recomendamos a partir dos achados, que as atividades de prevenção às DST/AIDS no âmbito da escola, rompam com a visão heterossexista, normativa e biologicista. Nesse contexto, a Enfermeira deve produzir/readequar novas tecnologias educativas que favoreçam o processo educação em saúde, valorizando as habilidades e aspirações dos adolescentes.

Descritores: Adolescência; Promoção da saúde; Tecnologia educacional; Educação em saúde.

\section{ABSTRACT}

This study addressed the use of educational technology as a strategy for health education among the teenagers in the school. Data collection occurred between April and May of 2007 in a public school in the city of Fortaleza-CE, through a cycle of four educational workshops held with 30 teenagers. The workshops had the intent to promote discussion / action from the participants on the themes: sexuality, gender, STD/AIDS and contraceptive methods. Study of research-action type of qualitative approach, backed by the pedagogical model of Paulo Freire. The results showed gaps in knowledge about the ways to infection by STDs and appropriate use of contraceptive methods. Another relates to issues of gender that seem to influence the quality of life of young people in the study. The use of educational technologies could arouse among adolescents, a rethink on the experience of sexual and reproductive health from the perceived vulnerabilities. According to the findings recommend that the activities of STD/AIDS prevention within the school, break with the vision heterossexist, normative and biological. In this context, the nurse should produce/readjust new technologies that support the educational process in health education, valuing the skills and aspirations of adolescents.

Descriptors: Adolescents; Promotion of health; Educational technology; Health Education.

\section{RESUMEN}

Este estudio se dirigió a la utilización de la tecnología educativa como una estrategia de educación para la salud entre los adolescentes en la escuela. El estudio se llevó a cabo entre los meses de abril y mayo de 2007 en una escuela pública en la ciudad de Fortaleza-CE, a través de un ciclo de cuatro talleres educativos con 30 adolescentes. Los talleres tuvieron la intención de promover el debate y acción de los participantes sobre los temas: sexualidad, género, ETS/sida y los métodos anticonceptivos. Estudio de investigación-acción tipo de enfoque cualitativo, respaldado por el modelo pedagógico de Paulo Freire. Los resultados mostraron lagunas en los conocimientos acerca de las maneras a la infección por enfermedades de transmisión sexual y el uso adecuado de métodos anticonceptivos. Otro se refiere a las cuestiones de género que parecen influir en la calidad de vida de los jóvenes en el estudio. El uso de tecnologías de la educación podría despertar entre los adolescentes, un replanteamiento de la experiencia de la salud sexual y reproductiva de la percepción de vulnerabilidad. Según las conclusiones recomiendan que las actividades de ETS/SIDA dentro de la escuela, romper con la visión heterossexista, normativo y biológicas. En este contexto, la enfermera debe producir/reajustar las nuevas tecnologías que apoyen el proceso educativo en la educación para la salud, la valoración de las aptitudes y las aspiraciones de los adolescentes.

Descriptors: Adolescencia; Promoción de la salud; Tecnología educacional; educación en salud. 


\section{NTRODUÇÃO}

A escola é considerada espaço crucial para o desenvolvimento de conhecimentos e habilidades junto aos seus integrantes e comunidade, visando à garantia de mudanças de comportamento, além de congregar por um período importante, crianças e adolescentes numa etapa crítica de crescimento e desenvolvimento.

A população escolar destacando adolescentes entre 11 e 19 anos, adoece menos que outros grupos etários e, de fato, tem taxas de morbidade e mortalidade mais baixas que da população em geral. Mas um olhar mais aprofundado evidencia aumento no número de infecções por DST e HIV, que associados a fatores socioeconômicos e culturais, têm profundas repercussões na qualidade de vida dessa população(1).

Consideramos que a adolescência é uma etapa crucial do desenvolvimento do indivíduo, e marca não só a aquisição da imagem corporal definitiva como também a estruturação final da personalidade. A Organização Mundial da Saúde - OMS considera a adolescência como a segunda década da vida, de 10 a 19 anos. Já a lei brasileira considera adolescência a faixa etária de 12 a 18 anos; assim, há uma divergência entre a fixação etária do Estatuto da Criança e do Adolescente - ECA e da OMS, também adotada pelo Ministério da Saúde ${ }^{(2)}$.

A Pesquisa Nacional por Amostra de Domicílios PNAD do ano de 2006, evidencia que quase metade $(49,6 \%)$ das famílias brasileiras, conta com, pelo menos, um de seus componentes com idade de até 14 anos. Destaca também, crescimento na taxa de adolescentes que freqüentam a escola na última década, atingindo, em $2005,81,7 \%{ }^{(3)}$.

Em relação às questões sexuais e reprodutivas, $32,8 \%$ dos adolescentes brasileiros, com faixa etária entre 12 e 17 anos, já haviam tido relações sexuais. Destes, $61 \%$ eram homens e $39 \%$ mulheres. Contudo, 9,5\% de adolescentes entre 15 e 19 anos ( $82 \%$ mulheres e $18 \%$ homens) vivenciam algum tipo de união, com vida sexual ${ }^{(4)}$. Realidade, muitas vezes, permeada pelo despreparo e inabilidade dos adolescentes frente a essas temáticas, acrescentado à falta de conhecimentos específicos.

Ainda nesse contexto Brandão e Heilborn ${ }^{(5)}$ referem que a primeira relação sexual não é um evento sistematicamente planejado com antecedência. A maioria dos jovens quando indagados sobre suas primeiras expectativas no momento do primeiro intercurso sexual divergem claramente em suas opiniões. Os homens adotam a ideologia da masculinidade $e$ as mulheres da passividade, ou seja, a mulher não espera que a primeira relação sexual ocorra tão precocemente.

Essa divergência, características da interiorização dos papéis de gênero, na qual o homem deve representar um papel ativo e a mulher não devem pensar muito na sexualidade, contribui para uma representação espontaneísta do sexo, convertendo em uma dificuldade de negociar e se prevenir das DST, pois o sexo é relegado a algo que não precisa ser discutido e muito menos planejado.

Diante da atual política de atenção a saúde sexual e reprodutiva de adolescentes, a maioria dos serviços de saúde, destacando a atenção primária à saúde, não possuem ações voltadas especificamente para essa população, particularmente na abordagem da sexualidade numa perspectiva ampliada, que considere a orientação sexual, as questões de gênero, vulnerabilidades e não meramente a esfera biológica/reprodutiva ${ }^{(6)}$.

No entanto é preciso incorporar que o conceito de saúde reprodutiva está associado ao de promoção da saúde, e em todos os aspectos do sistema reprodutivo, suas funções e processos, implicando que a pessoa possa ter uma vida sexual segura, satisfatória e liberdade para decidir sobre sua sexualidade. Isto inclui igualmente a saúde sexual, cuja finalidade é a melhoria da qualidade de vida e das relações pessoais e não apenas a assistência relativa à reprodução e às DST. A saúde sexual possibilita experimentar a sexualidade de forma agradável e segura, baseada na auto-estima, que implica numa abordagem positiva da sexualidade humana e no respeito mútuo nas relações sexuais ${ }^{(7)}$.

Resgatando os conceitos de Educação em Saúde, Naiddo e Wills ${ }^{(8)}$ referem que esta é uma aprendizagem sobre saúde, que envolve a capacidade permanente ou disposição para mudança de cada sujeito. A educação em saúde também é compreendida como atividade principal da promoção da saúde para desenvolver autonomia, responsabilidade das pessoas e comunidades com sua saúde, além de ser uma prática social crítica e transformadora amplamente utilizada na prevenção às DST/HIV/AIDS.

Nessa perspectiva, buscando implementar ações de educação em saúde, as tecnologias são processos concretos que, a partir de uma experiência cotidiana e da pesquisa, podem desenvolver um conjunto de atividades que serão produzidas e controladas pelos seres humanos, podendo ser veiculados como artefatos ou como saberes (estruturados), sistematizados e com controle de cada passo do processo. A tecnologia, então, contribui para produzir conhecimentos a serem socializados, para dominar processos e produtos, a fim de transformar a utilização empírica em uma abordagem científica ${ }^{(9)}$.

As tecnologias neste estudo se referem às estratégicas educacionais utilizadas para estimular comportamentos saudáveis através da aprendizagem de habilidades para os cuidados da saúde no enfrentamento do processo de saúde-doença entre 
adolescentes, nos agravos que requerem mudanças permanentes ou temporárias e na percepção de risco e/ou vulnerabilidade frente às DST/HIV/AIDS e gravidez precoce.

Diante do exposto, o objetivo deste estudo é abordar o processo de educação em saúde através do uso de tecnologias educativas junto a adolescentes no contexto escolar. Em vista disso, advogamos uma educação transformadora que, responda às necessidades dos participantes, e, venha colaborar com a experimentação de novas abordagens educativas da enfermeira no âmbito escolar, bem como, a criação de instrumentos tecnológicos efetivos que possam favorecer o cuidado de enfermagem em relação à saúde do adolescente.

\section{MÉTODO}

O estudo é do tipo pesquisa-ação, numa perspectiva qualitativa, apoiado no Modelo Pedagógico de Paulo Freire - Ciclo de Cultura. A pesquisa-ação é uma pesquisa social com base empírica realizada em estreita associação com uma ação ou com a resolução de um problema coletivo e na qual os pesquisadores e os participantes, representativos da situação ou do problema, estão envolvidos de modo cooperativo e participativo ${ }^{(10)}$.

o Círculo de Cultura foi utilizado com intuito de contribuir para a promoção de conhecimento, reflexão e decisão dos adolescentes no ato de cuidarse e serem protagonistas. Nesta perspectiva, o método de Paulo Freire permite aos participantes e pesquisadores, elaborar processos de conhecimento e ação a partir de suas reais necessidades, e em conjunto, articular alternativas para resolvê-los, facilitando o processo de cuidado ${ }^{(11)}$.

A definição do campo de estudo surgiu a partir da inserção das autoras em um Projeto de Extensão Universitária intitulado: "AIDS: Educação e Prevenção", promovido pelo Departamento de Enfermagem da Universidade Federal do Ceará-UFC; e do projeto de pesquisa "Tecnologia Educacional e os modelos de educação em saúde nas ações de enfermagem e promoção da saúde", cadastrado no Conselho Nacional de Desenvolvimento Científico e Tecnológico-CNPQ, processo 409365/2006-8.

O estudo foi realizado numa escola pública municipal localizada em Fortaleza-CE. Consistiu na apresentação do Projeto à direção da instituição e escolha da série a ser trabalhada. Convidamos uma turma de 30 alunos, com faixa etária de 14 a 18 anos, cursando o segundo ano do ensino médio, para participarem das atividades, por indicação da própria escola. Cada oficina teve média de 25 a 30 participantes.

A coleta de dados ocorreu entre os meses de abril e maio de 2007 a partir de encontros semanais, integrados com as atividades de aula, em momentos concedidos pelos professores, com o consentimento da direção da escola.

Para alcançarmos os objetivos propostos, registramos as informações em um diário de campo, com dados pertinentes às oficinas e observação das pesquisadoras. A primeira fase do estudo caracterizou-se pela observação e escuta dos adolescentes a partir de uma roda de conversas para se obter uma visão do interesse do grupo e apresentação dos objetivos do Projeto. Por conseguinte, os adolescentes tiveram um debate sobre as temáticas que mais lhe interessavam, voltados à Saúde Sexual e Reprodutiva. Sendo assim, o trabalho se deu a partir do processo dialético entre o diálogo e elaboração das vivências relacionadas à sexualidade.

Em seguida, passamos a desenvolver as oficinas educativas apoiadas no Círculo de Cultura, abordando as temáticas escolhidas pelos adolescentes. Optou-se por utilizar a metodologia de Oficinas em dinâmica de grupo, prática de intervenção psicossocial adaptável a diversos contextos. A Oficina tem suas bases e forma de organização originárias da pesquisa-ação, grupos operativos e pedagogia da autonomia ${ }^{(11)}$.

A realização das oficinas deu-se através da Análise da Demanda - Levantamento; Pré-análise da Problemática do Contexto e do Grupo Planejamento; Levantamento dos Temas-Geradores e Definição do Foco - Execução e Avaliação. Desta forma, as oficinas educativas tiveram as seguintes etapas:

1. Levantamento: necessidades dos adolescentes, tendo em vista as prioridades, detectadas no momento de apresentação inicial. Como forma de conhecermos suas expectativas, os adolescentes escreveram questões que gostariam de discutir, colocando-as sem identificação em uma caixa para debate;

2. Planejamento: ciclo de quatro oficinas, nas quais utilizamos técnicas de sensibilização, dinamização, comunicação e reflexão, a fim de propiciar a formação de vínculo grupal;

3. Execução: implementação das oficinas, divididas em temas centrais: Sexualidade, Gênero, DST e AIDS, incluindo o uso de métodos contraceptivos. Esta etapa baseou-se em exposição dialogada e uso de materiais educativos preconizados pelo Ministério da Saúde.

4. Avaliação: desenvolvimento de uma tecnologia leve, por meio da confecção de um material educativo - Fanzine, construído pelos adolescentes, levando em consideração os conhecimentos e habilidades adquiridos na intervenção. O material é originado da abreviação de fanatic magazine, semelhante a 
uma revista, é uma publicação despretensiosa e artesanal, feita com diversos materiais artísticos. Engloba vários temas, com especial incidência de histórias em quadrinhos ${ }^{(12)}$.

Para representarmos os achados do estudo, categorizamos os acontecimentos pertinentes à implementação das oficinas educativas, por meio de duas etapas: o inventário, que é o ato de isolar os elementos presentes nas falas dos adolescentes; e a classificação, que é a divisão de forma organizada dos elementos de mensagem ${ }^{(13)}$.

Os resultados são apresentados em quatro categorias oriundas das oficinas educativas: Sexualidade; Questões de gênero; Dialogando sobre DST e AIDS e Conhecimento dos adolescentes sobre métodos contraceptivos, categoria na qual apresentamos a produção do Fanzine.

Destacamos que, o presente projeto foi aprovado pelo comitê de ética em Pesquisa da Universidade Federal do Ceará-UFC, Protocolo $N^{\circ} .08 / 07$, atendendo a Resolução $n^{\circ} 196 / 96$ do Conselho Nacional de Saúde, destacando o item IV, no qual se refere ao termo de consentimento livre e esclarecido.

\section{RESULTADOS E DISCUSSÃO}

\section{Sexualidade na voz dos adolescentes}

A estratégia inicial consistiu na formulação de perguntas que contemplassem as dúvidas dos adolescentes. A idéia teve o propósito de despertar os jovens a uma reflexão crítica e problematizadora, permitindo que os saberes individuais fossem coletivizados numa experiência comum.

Ao resgatarmos as narrativas oriundas das perguntas formuladas e respondidas pelos adolescentes, percebemos incertezas quanto à idade para a iniciação sexual. Além disso, teceram conjecturas errôneas sobre a relação sexual e as modificações no corpo. Algumas falas dos participantes evidenciam inconsistências nos saberes sobre estas temáticas, realidade que pode vir a ter influência na vivência da sexualidade, como observamos nos discursos a seguir:

A iniciação sexual aos doze anos de idade é cedo ou tarde?

-È cedo, porque o organismo não ta preparado;

- Isso depende de cada um

-Se for por amor, porque não?

Porque as mulheres botam mais corpo depois da $1^{a}$ relação?

-Tem gente que sabe se mulher é virgem só pelo corpo

-Tem gente que diz: deu tanto que colocou corpo -Se deu com o produto, todo mundo aqui fala isso!

Percebe-se que há uma preocupação com a idade da iniciação sexual e sua ligação com mudanças no corpo, principalmente nas meninas, segundo os próprios adolescentes. As concepções de sexualidade parecem estar relacionadas ao contexto cultural, visto que grande maioria possui as mesmas concepções a respeito e que estas são comuns entre outros adolescentes que conhecem ${ }^{(5)}$.

Para Heilborn ${ }^{(14)}$ essas concepções podem influir sobre os sentimentos e atitudes entre meninos e meninas na primeira relação sexual. Para as mulheres o que motiva é o amor, seguido da curiosidade, e por último o prazer, sobretudo entre as adolescentes de 15 anos ou menos. A autora defende a trilogia feminina medo-dor-nervosismo, sugerindo que as mulheres têm pouco ou nenhum controle sobre o acontecimento, correspondente aos homens ao nervosismo-excitação-satisfação, que exprime uma realidade inteiramente diferente.

Nessa perspectiva, a enfermeira deve esclarecer sobre as mudanças ocorridas, o que favorece a aceitação desses, em meio às transformações da adolescência, reduzindo sentimentos de vergonha e constrangimento em relação ao corpo. Esse fato pode incidir na prevenção as DST/HIV/AIDS na medida em que o adolescente desenvolve a auto-estima e percebe com mais atitude seu contexto de vulnerabilidade.

Diante do contexto descrito, acreditamos que enfermeiro deve dialogar abertamente sobre o assunto, não de forma moralista, mas respeitando as diferenças culturais e os direitos sexuais e reprodutivos dos adolescentes e expondo as repercussões da vivência da sexualidade. Sendo a enfermeira integrante da equipe de saúde da família e tendo como espaço de atuação a escola, deve abordar junto a sua clientela as questões sexuais muito além do aspecto biológico, e reconhecendo outros fatores que incidem na antecipação da vida sexual, considerando o contexto socioeconômico e cultural no qual estes adolescentes estão inseridos.

\section{Discutindo sobre as questões de gênero}

Para despertarmos a discussão entre os adolescentes sobre a temática, foram distribuídas 11 frases, entre dois grupos divididos em meninos e meninas, as quais surgiram a partir de alguns depoimentos, sugeridos informalmente pelos adolescentes durante as oficinas. Para instigar a problematização entre os adolescentes ambos receberam as mesmas frases.

Para desenvolver no grupo uma maior percepção quanto às questões de gênero, instruímos o grupo a classificar as frases como inerentes ao sexo feminino ou masculino, à medida que as opiniões de meninas e meninos, acerca do mesmo assunto, convergiam.

Após a realização da dinâmica, procedemos a uma grande roda de discussão, onde os grupos poderiam refletir sobre a temática. Os meninos 
atribuíram à maioria das frases como pertinentes a ambos os sexos, enquanto as meninas classificaramnas como exclusivas do sexo masculino.

$\mathrm{Na}$ divisão das falas, percebe-se que, para os adolescentes do sexo masculino, as questões relativas à necessidade de terem várias relações sexuais e conduzirem o ato sexual, é sinônimo de virilidade. A questão emocional foi abordada e descrita, pelos meninos, como inaceitável e exclusiva do sexo feminino. Quanto ao uso do preservativo os meninos se caracterizaram como responsáveis. A seguir, alguns dos depoimentos que refletem a opinião dos meninos, diante de atitudes consideradas inerentes ao sexo masculino.

Está sempre com desejo e pronto para o sexo

Não pode mostrar seus sentimentos

Deve tomar a iniciativa no uso do preservativo e tê-lo sempre consigo

Deve começar sua vida sexual o mais cedo possível

Reportando às colocações feitas pelas meninas, observa-se consentimento, diante das questões relatadas como masculinas, com a idéia de que 0 homem deve conduzir $O$ ato sexual. Elas acrescentam, também, que devido as suas necessidades fisiológicas serem mais proeminentes, são os homens que devem excitar a parceira até o clímax sexual. As adolescentes ainda referiram que o uso do preservativo deve ser de iniciativa do sexo oposto.

A seguir algumas narrativas das meninas:

Deve ser ativo durante o sexo

Deve tomar a iniciativa do uso do preservativo e tê-lo sempre consigo

É responsável pela excitação e pelo orgasmo

É responsável em caso de gravidez

Deve sempre tomar a iniciativa da relação sexual

Os achados do estudo corroboram com pesquisa realizada em 406 adolescentes de 15 a 19 anos de idade $^{(14)}$, visto que as mulheres do estudo mostraram-se mais vulneráveis às DST/AIDS, pois substituíram o preservativo masculino por outros métodos na última relação sexual colocando o amor como categoria de proteção, enquanto os homens permaneceram utilizando largamente o condom, provavelmente por estarem inseridos em relacionamentos não estáveis.

Diante da realidade vivida pelos adolescentes, é nítida a ambigüidade, nos papéis de gênero, na visão dos participantes do estudo, visto que, algumas colocações, inerentes a homens e a mulheres, definidas pelo grupo, foram concebidas como prioritariamente masculinas, evidenciando certo controle e desvalorização da sexualidade feminina, o que de certa forma, aumenta sua vulnerabilidade. Nessas circunstâncias, constatamos que, são necessárias transformações na educação sexual dos adolescentes, com o objetivo de incentivar 0 protagonismo dessa população frente à sua vida, fortalecendo o diálogo com os pais, escola, familiares e a construção de políticas públicas integrais, voltadas para o empoderamento dos adolescentes ${ }^{(15)}$.

Sob esse olhar é preciso repensar essas questões, travando esse diálogo nos diversos espaços da sociedade, inclusive, expandindo essa atitude para todo o entorno escolar, por este agregar, em um grande espaço e tempo, crianças e adolescentes, o que conseqüentemente torna a escola um ambiente propício para provocar mudanças em nossa sociedade.

$\mathrm{Na}$ prática, a oficina pode estimular os adolescentes à reflexão acerca de determinadas crenças que permeiam a sexualidade, envolvendo as questões de gênero, em uma dimensão, até então despercebida, em que homens e mulheres têm iguais direitos e responsabilidades na vida sexual e na vida como um todo, sendo sua única diferença, meramente, biológica.

\section{Dialogando sobre DST e AIDS}

Para discutirmos sobre as DST, iniciamos com a apresentação de folderes veiculados pelo Programa Nacional de DST/AIDS, contendo informações sobre as doenças e formas de contágio, além de álbum seriado ilustrado. Tais materiais, em conjunto com as informações discutidas pelo grupo, favoreceram o processo de comunicação entre os adolescentes e as pesquisadoras acerca de DST e AIDS.

No decorrer da discussão, observamos que os adolescentes possuem conhecimentos relacionados aos sinais e sintomas das DST, restritos à patologia, mas não demonstram preocupação quanto ao contágio e prevenção das doenças. A dificuldade de se verem como indivíduos suscetíveis faz com que fiquem em situação de vulnerabilidade. Os adolescentes demonstraram, em seus discursos, alguns entraves e inconsistências no que diz respeito às infecções:

Como é feito o tratamento da sífilis e se cura totalmente?

-È aquela que tem escorrimento?

-A pessoa tem febre?

-Toda DST tem escorrimento?

-E pelo beijo pega? Eu acho que não

- Se tratar no inicio pode ter cura, eu acho

Diante dos vários depoimentos e apesar da maioria dos adolescentes ter informações acerca das medidas de prevenção das DST/AIDS, esse conhecimento ainda não parece ser suficiente para assegurar comportamentos sexuais seguros. A maior parte desse conhecimento é proveniente da televisão, Internet e amigos e consiste em um conhecimento, muitas vezes superficial, sem conseguir sensibilizá-los sobre o risco das inúmeras 
doenças sexualmente transmissíveis e de adoção de um comportamento seguro ${ }^{(16)}$.

A incidência das DST/AIDS tem aumentado na população em geral, sendo que entre adolescentes o número de contaminados está cada vez maior. Esse crescimento pode ser resultado da percepção errônea que, ainda hoje, grande parte da população tem de não ser vulnerável a adquirir qualquer infecção, devido à presença da atitude que reforça a idéia e risco que o problema DST/AIDS nunca vai acontecer comigo $^{(17)}$.

Outro fato remete-se a crescente feminização da epidemia, sobretudo, entre mulheres mais jovens e pobres, com menor acesso à medidas assistenciais e educativas preventivas, tendo em mente, ainda, que estudos demonstram que grande parte dos indivíduos que vivem com HIV/AIDS, na atualidade, possivelmente, a contraíram ainda na adolescência.

A prevenção da AIDS, bem sucedida (ou seja, o que levaria à responsabilidade em relação ao autocuidado), tem demonstrado que requer três elementos: informação/educação; serviços de saúde e sociais, bem e ambiente de apoio. Assim, a vulnerabilidade pessoal aumenta com a falta de informações precisas, relevantes e abrangentes; incluindo a inabilidade para tratar dessas questões, as quais, acrescentamos também, o fortalecimento do acesso à serviços específicos que consigam contemplar as necessidades dos adolescentes na medida em que visam sustentar e implementar mudanças comportamentais no âmbito dessas temáticas ${ }^{(18)}$.

Acreditamos ainda que, muitas vezes, o despreparo das pessoas, em geral, de pais e de professores, no trato às questões ligadas à sexualidade com adolescentes, se restringe à ausência de diálogo ligada a barreiras adquiridas e a falta de comunicação sobre sexualidade favorecendo um maior risco de contaminação as DST/AIDS.

\section{O conhecimento dos adolescentes sobre métodos contraceptivos}

A dinâmica proposta consistiu em uma roda de conversas, concomitante a exposição das pesquisadoras sobre os métodos, seguida de uma demonstração sobre a utilização correta do preservativo masculino, a pedido dos adolescentes, momento em que puderam participar, voluntariamente, demonstrando seus conhecimentos sobre o devido uso. Neste encontro, utilizou-se materiais ilustrados, de autoria do Ministério da Saúde, contendo fotos dos métodos e as respectivas indicações sobre o uso.

No presente estudo, a maioria dos adolescentes de ambos os sexos mostrou conhecer pelo menos um método anticoncepcional, corroborando assim os achados da pesquisa da BEMFAM ${ }^{(19)}$ que revela que praticamente $100 \%$ dos jovens brasileiros (de 15 a 24 anos) conhecem algum método não refletindo, no entanto, no modo correto de uso.

O preservativo masculino foi o mais referido entre meninos e meninas, o que pode estar relacionado tanto à sua utilização como forma de prevenção da gravidez como à forte influência das campanhas de prevenção das DST/AIDS. Contudo, as mulheres apresentaram maiores percentuais de conhecimento em todos os métodos pesquisados, o que provavelmente reflete a tradição do uso de contracepção como exclusiva atribuição feminina.

Apesar dos conhecimentos, os adolescentes relataram dificuldades no uso, principalmente ligadas ao preservativo. Corroborando com os achados do estudo no que se refere aos entraves, outra pesquisa realizada, com jovens que usam irregularmente a contracepção, revelam atitudes negativas, tais como medo de interferência no desempenho sexual e medo de que pareça haver premeditação do ato ${ }^{(17,20)}$. Dentre outras implicações, dificuldades sócioculturais no acesso à contracepção destaca-se o contexto cultural, religioso, mitos e crenças.

Os resultados evidenciados no estudo apontam para a necessidade de um maior aporte no âmbito do Planejamento Familiar para adolescentes. Apesar da intervenção ter sido em um reduzido espaço de tempo, evidenciou claramente que essa população tem entraves quando ao uso correto e acesso aos métodos contraceptivos e de prevenção.

Com intuito de avaliarmos as repercussões junto aos adolescentes e resgatando os temas abordados nas quatro oficinas, seguimos com a construção de um instrumento tecnológico a partir do "olhar" do grupo. Nessa perspectiva, acreditamos que a estratégia tradicional do cuidar/cuidado no qual o profissional é o detentor do saber/fazer não é mais cabível nos dias de hoje, por isso neste encontro, pactuamos a criação de um material que fosse construído a partir da percepção dos adolescentes. Nesse ínterim, da construção do instrumento, utilizamos recortes de revistas que ilustrassem os sentimentos dos adolescentes. Cola, tesoura e lápis, foram utilizados com o intuito de despertar a capacidade criativa do grupo.

O instrumento tecnológico criado pelos participantes foi à expressão de arte através de um Fanzine já citado anteriormente. Apenas 17 alunos participaram da construção do material, com destaque para os desenhos referentes ao aparelho reprodutivo, por exemplo, desenhos do útero e do pênis, feitos a partir de recortes de revista. O preservativo foi abordado em vários desenhos, como idéia principal da mensagem: "eu, ele e a camisinha".

Os desenhos puderam evidenciar que os participantes do estudo ainda vêm às questões 
sexuais e reprodutivas de forma restrita ligada principalmente à esfera biológica e não integrada a uma visão que contemple a sexualidade como inerente a qualidade de vida, ao prazer e a felicidade. Este fato é preocupante, pois pode contribuir para uma visão limitada da sexualidade, dificultando a adoção de práticas preventivas e a manutenção do vínculo e do afeto.

\section{CONSI DERAÇÕES FI NAIS}

Diante do que foi exposto, percebemos que o trabalho de promoção à saúde sexual e reprodutiva dos adolescentes necessita integrar a idéia de cidadania e direitos humanos, aos temas da sexualidade, gênero, diversidade sexual e DST/AIDS.

É nítida a necessidade de debatermos continuamente as diferenças e as relações entre os gêneros, conscientizando os adolescentes de que os papéis associados ao masculino ou ao feminino não são resultado da "natureza" da diferença entre os sexos, mas socialmente construídos, dando conta do contexto socioeconômico em que o sexo e as vivências de gênero acontecem.

Essa divergência entre as opiniões dos adolescentes, características da interiorização dos papéis de gênero, na qual o homem deve representar um papel ativo e a mulher não devem pensar muito na sexualidade, contribui para uma representação espontaneísta do sexo, convertendo em uma dificuldade de negociar e se prevenir das DST, pois o sexo é relegado a algo que não precisa ser discutido e muito menos planejado. Assim, desconstruir certas noções errôneas criadas socialmente entre os adolescentes é primordial para a melhoria de sua qualidade de vida, e é a partir daí que o enfermeiro deve colaborar com a decodificação a complexidade dos sentimentos e atitudes que perpassam a saúde dessa população.

Neste contexto as atividades de prevenção às DST/AIDS no âmbito da escola e ESF, devem romper com a visão heterossexista e normativa, visto que como citado anteriormente, as campanhas preventivas e os programas voltados a saúde sexual e reprodutiva, ainda são mais voltados para o público heterossexual e que se encontram em um relacionamento estável.

Pontuamos a necessidade de que o Sistema Único de Saúde - SUS garanta em suas diretrizes, escolhas preventivas para as distintas formas de relacionamento afetivo-sexual entre os adolescentes em diferentes contextos de relações de gênero e não somente na perspectiva de evitar a concepção.

É preciso trazer para esse debate também a família, visto que, ela exerce papel fundamental na formação do individuo saudável. Diante da notória dificuldade existente na relação entre adolescentes e a entrada conturbada na vida sexual, é imprescindível o desenvolvimento de iniciativas e estratégias que incluam programas de orientação sexual e preparação dos pais em habilidades informativas e comunicativas.

Durante o estudo verificamos a necessidade de criação de espaços e escuta na escola e nos serviços de saúde, específicos para os adolescentes, que permitam o estabelecimento de um vínculo com os profissionais e educadores, proporcionando um atendimento mais qualificado, visto que apesar de algumas políticas públicas atuais como o Projeto Saúde e Prevenção nas escolas - SPE, estimularem essa interação, ainda não conseguiram superar as barreiras para integração entre educação e saúde.

O uso de tecnologias educativas foi primordial no desenvolvimento do processo educativo proposto, visto que tenta superar o modelo tradicional para o foco da co-produção de saber e autonomia, onde os adolescentes tornam-se centrais no processo educativo. Acrescentamos ainda que as oficinas permitiram aos adolescentes, por meio da metodologia do Círculo de Cultura, a aquisição de novos conhecimentos sobre as temáticas e mesmo que não gerem uma mudança de comportamento imediata, podem favorecer um repensar de suas práticas e atitudes para o futuro.

No tocante ao papel do enfermeiro, é urgente reformular o processo de trabalho, a partir da criação de novos saberes que favoreçam tanto a formação profissional, quanto a capacidade de produzir e readequar novos recursos tecnológicos do tipo educativos. Visto que alguns materiais produzidos pelo Ministério da Saúde e Secretarias Municipais de Saúde, voltados para a prevenção das DST/HIV/AIDS, como folderes, cartilhas, cartazes e álbuns seriados, não contemplam em sua linguagem as especificidades de algumas populações em situação de vulnerabilidade.

Assim, reforçamos a necessidade do Enfermeiro em produzir novas tecnologias educacionais, extrapolando as atividades de educação em saúde baseada em ações pontuais e que não reconhecem as verdadeiras necessidades, desejos e aspirações de seus integrantes. Nesse sentido o Fanzine se configura como tecnologia educacional visto que a idéia de expressão através dos quadrinhos, emergiu através dos próprios participantes, favorecendo o acolhimento e o vínculo entre $\mathrm{o}$ adolescente e enfermeira.

\section{REFERÊNCIAS}

1. Cerqueira MT. A Construção da Rede Latino Americana de Escolas Promotoras de Saúde. In: Ministério da Saúde; Organização Pan-Americana de Saúde. Escolas promotoras de saúde: experiências do Brasil. Série Promoção da Saúde; no 6. 1st ed. Brasília: Ministério da Saúde; 2007. 
2. Ministério da Justiça. Estatuto da Criança e do Adolescente. 12 anos. Edição especial. Brasília: Ministério da Justiça; 2002. 224 p.

3. Instituto Brasileiro de Geografia e Estatística [Internet]. Brasília: Ministério do Planejamento, Orçamento e Gestão (BR) [cited 2009 feb 27]. Pesquisa Nacional por Amostra de Domicílios. Síntese de Indicadores 2005. Available from: http://www. ibge.gov.br/home/estatistica/populacao/t rabalhoerendimento/pnad2005/default. shtm.

4. Fundo das Nações Unidas para a Infância- UNICEF. A voz dos adolescentes. Genebra: UNICEF; 2002.

5. Brandão ER, Heilborn ML. Sexualidade e gravidez na adolescência entre jovens de camadas médias do Rio de Janeiro, Brasil. Cad. Saúde Pública [Internet]. 2006 [cited 2009 feb 16];22(7):1421-30. Available from: http://www. scielosp.org/pdf/csp/v22n7/07.pdf. 6. Oliveira TC, Carvalho LP, Silva MA. O enfermeiro na atenção à saúde sexual e reprodutiva dos adolescentes. Rev Bras Enferm [Internet]. 2008 [cited 2009 feb 16];61(3):306-11. Available from: http://www. scielo.br/pdf/reben/v61n3/a05v61n3.pdf

7. United Nations. Report of the International Conference on Population and Development. Cairo, 5-13 September 1994 [Internet]. New York: United Nations publication; 1995 [cited 2009 feb 16]. 197p. Available from: http://www.unfpa.org/upload/lib_pub_file/570 filena me finalreport_icpd_eng. pdf.

8. Naidoo J, Wills J. Health Promotion - foundations for practice. London: Bailliére Tindall; 1994.

9. Monteiro S, Vargas E, Cruz M. Desenvolvimento e uso de tecnologias Educacionais no Contexto da AIDS e da Saúde Reprodutiva: Reflexões e Perspectivas. In: Educação, Comunicação e tecnologia educacional. Org: Monteiro S. Vargas E. Rio de Janeiro: Editora Fiocruz; 2006. p.27-34

10. Newman JM. Action reaserch: A brief overview. Forum: Qualitative Social Research [Internet]. 2000 [cited 2009 feb 16];1(1). Available from: http://www. qualitative-

research.net/index. php/fqs/article/view/1127/2508.

11. Brandão CR. O que é o método de Paulo Freire. Coleção Primeiros Passos. São Paulo: Brasiliense; 2004.

12. Edgard G. Algo sobre Fanzine [Internet]. Campinas: Kplus; 2000 [update 2000 mar 01; cited 2009 feb 16]. Available from: http: // kplus. cosmo.com. br/materia. asp? $c 0=41 \& r v=L i$ teratura.

13. Rodrigues MPS, Leopardi MT. O método de análise de conteúdo. Fortaleza: Fundação Cearense de Pesquisa e Cultura; 1999.

14. Borges ALV. Relações de gênero e iniciação sexual de mulheres Adolescentes. Rev. esc. enferm. USP. [Internet]. 2007 [cited 2009 feb 16]; 41(4):597-604. Available http://www. scielo.br/pdf/reeusp/v41n4/08.pdf.
15. Borges ALV, Schor N. Início da vida sexual na adolescência e relações de gênero: um estudo transversal em São Paulo, 2002, Brasil. Cad. Saúde Pública [Internet]. 2005 [cited 2009 feb 16];21(2):499-507. Available from: http://www. scielo. br/pdf/csp/v21n2/16. pdf.

16. Doreto DT, Vieira EM. O conhecimento sobre doenças sexualmente transmissíveis entre adolescentes de baixa renda em Ribeirão Preto, São Paulo, Brasil. Cad. Saúde Pública [Internet]. 2007 [cited 2009 feb 16];23(10):2511-16. Available from: http://www.scielosp.org/pdf/csp/v23n10/26.pdf.

17. Carmo R, Sand ICPV. O Discurso dos adolescentes sobre a vida sexual na adolescência. Rev. Eletr. Enf. [Internet]. 2007 [cited 2009 feb 16];09(2):417-31. Available from: http://www.fen.ufg. br/revista/v9/n2/v9n2a10.htm. 18. Ávila MB. Direitos sexuais e reprodutivos: desafios para as políticas de saúde. Cad. Saúde Pública [Internet]. 2003 [cited 2009 feb 16]; 19(suppl.2):S465-9. Available from: http://www.scielosp.org/pdf/csp/v19s2/a27v19s2.pdf 19. Sociedade Civil Bem-Estar Familiar no Brasil BENFAM. Adolescentes, jovens e a pesquisa nacional sobre demografia e saúde: um estudo sobre fecundidade, comportamento sexual e saúde reprodutiva. Rio de Janeiro: CDC/UNICEF; 1999.

20. Alves CA, Brandão ER. Vulnerabilidades no uso de métodos contraceptivos entre adolescentes e jovens: interseções entre políticas públicas e atenção à saúde. Ciênc. saúde coletiva [Internet]. 2009 [cited 2009 feb 16];14(2):661-70 Available from: http://www.scielo.br/pdf/csc/v14n2/a35v14n2.pdf.

Artigo recebido em 18.11.07.

Aprovado para publicação em 31.03.09. 